\title{
Juventudes e produção de subjetividades no contexto de acumulação flexivel do capital
}

\author{
Youth and the production of subjectivities in the context of \\ flexible accumulation of capital
}

Carlos Soares Barbosa1

\section{Resumo}

Este texto visa a refletir os modos de perceber, sentir e estar no mundo, assim como os sentidos e percepções que os estudantes da Educação de Jovens e Adultos (EJA) na etapa do Ensino Médio, moradores das favelas da Rocinha, Jacarezinho e Manguinhos, imprime a participação politica e a relação trabalho e educação no atual contexto de desemprego estrutural e de crescimento das relações de trabalho flexíveis e precarizadas. Trata-se de reflexões preliminares da pesquisa qualitativa, ainda em andamento, que tem o Materialismo Histórico Dialético como matriz teórica e metodológica. Os dados das entrevistas de roteiros semi-estruturados, aplicados até o momento a 32 estudantes de duas escolas da rede estadual de educação do Rio de Janeiro, na faixa etária de 18 a 29 anos de idade, e a realização de dois grupos focais, indicam que o individualismo, o imediatismo, a incerteza, o consumismo e o ceticismo em relação à política institucionalizada são uma construção histórico-cultural; subjetividades produzidas no conjunto das mudanças efetuadas no Brasil, em decorrência do regime de acumulação flexível do capital e da política neoliberal, adotada ao longo a década de 1990 e retomada no atual governo de Michel Temer.

Palavras-chave: Acumulação flexível. Subjetividade. Jovens.

\section{Abstract}

This text aims to reflect the ways of perceiving, feeling and being in the world, as well as the senses and perceptions that the students of the Education of Young and Adults (EJA) in the stage of High School, residents of the favelas of Rocinha,

\footnotetext{
1 Doutor em Políticas Públicas e Formação Humana (UERJ). Professor Adjunto da Faculdade de Educação da Universidade do Estado do Rio de Janeiro - Campus Maracanã. Pesquisador das áreas de Trabalho e Educação e Educação de Jovens e Adultos. E-mail: profcarlossoares@gmail.com.
} 
Jacarezinho and Manguinhos, implies to political participation and the relationship between work and education, in the current context of structural unemployment and the growth of flexible and precarious working relationships. These are preliminary reflections of the qualitative research, still in progress, that has the Historical Materialism Dialectic as a theoretical and methodological matrix. Data from interviews of semi-structured scripts, applied to 32 students from two schools of the state education network of Rio de Janeiro, aged 18 to 29 years, and the accomplishment of two focus groups, indicate that individualism, immediacy, uncertainty, consumerism and skepticism in relation to politics are a historical-cultural construction; subjectivities produced in the set of changes made in Brazil, due to the regime of flexible accumulation of capital and neoliberal politics, adopted throughout the decade of 1990 and resumed in the current government of Michel Temer.

Keywords: Flexible accumulation. Subjuncticity. Young people.

\section{Introdução}

Os dados do último Censo demográfico do Instituto Brasileiro de Geografia e Estatística (IBGE) indicaram que em 2010 os jovens representavam um quarto da população do país, o que equivalia a 51,3 milhões de jovens na faixa etária de 15 a 29 anos de idade. Dessa totalidade, 53,5\% trabalhavam, $36 \%$ estudavam e $22,8 \%$ trabalhavam e estudavam simultaneamente. Posteriormente, em 2013, a Secretaria Nacional da Juventude (SNJ) detalhou um pouco mais o perfil dos jovens brasileiros e indicou que entre os mais novos, na faixa de 15 a 17 anos, 65\% estudavam e 16\% trabalhavam, ao passo que entre os jovens de 25 a 29 anos, mais de $70 \%$ trabalhava ou estava procurando trabalho, enquanto apenas $12 \%$ apenas estudava.

A expressividade numérica da população juvenil brasileira nem sempre se fez acompanhada por políticas públicas que visassem assegurar o desenvolvimento integral dos jovens, o que os impulsionaram, ao longo de décadas, a uma luta cotidiana por visibilidade e pelo reconhecimento como sujeitos de direitos, com demandas e especificidades próprias. Esta situação foi relativamente revertida durante os governos de Lula da Silva e de Dilma Roussef, momento em que as questões da juventude ganharam espaços nas 
agendas governamentais e nos debates nacionais, cuja maior expressão foi a criação da SNJ, em 2004, e as políticas de juventude implementadas a partir de então.

Por se tratar de um conceito polissêmico, algumas considerações iniciais são necessárias quando se aborda a temática da juventude. A primeira, diz respeito ao entendimento sobre a faixa etária correspondente à juventude. No Brasil, o único dispositivo legal que delimita a faixa etária juvenil é o Estatuto da Criança e do Adolescente (ECA) que contempla os 18 anos como idade limite. Os organismos internacionais, que por muitos anos se basearam na faixa etária de 18 a 24 anos para caracterizar o grupo considerado como jovem, nos últimos tempos têm ampliado esta faixa para 30 anos de idade. A definição/delimitação da juventude a partir da idade cronológica não é consenso entre os teóricos. Para os sociólogos Lenoir (1996) e Bourdieu (1983) não é possivel tratar a "idade" como uma característica independente do contexto no qual ela toma sentido. Para os autores, as categorias "juventude" e "velhice" são construídas socialmente; resultado de uma luta entre gerações que busca definir relações de poder. Neste sentido, o importante não é definir a partir de que idade os sujeitos se tornam "jovens" ou "velhos", mas descrever os processos através dos quais são designados socialmente dessa forma. É por isso que para Bourdieu, a "juventude" é apenas uma palavra, pois não pode ser compreendida sem ser contextualizada, uma vez que sofre variação historicamente e em relação a outras categorias. Afinal, "somos sempre o jovem ou velho de alguém" (BOURDIEU, 1983, p.113).

A segunda consideração, diz respeito à definição de juventude e a imprecisão dos critérios que compõem essa categoria, já que se trata de uma categoria em constante mutação. Sposito (2005) informa que no fim dos anos 1980 a juventude era concebida como o momento de transição para a vida adulta, ou o momento de preparação para aquilo que o jovem viria a ser. Atualmente, discute-se a idéia de autonomia, independência econômica e também um conceito de juventude que é o de experimentação. Juventude, 
portanto, pode ser compreendida como a "fase da vida em que se inicia a busca de autonomia, marcada tanto pela construção de elementos da identidade pessoal e coletiva - como por uma atitude de experimentação" (SPOSITO, 2005, p. 89). Uma fase singular, visto que o modo como os jovens vivem essa etapa difere das gerações anteriores, já que os caminhos e contornos de entrada para a vida adulta se diversificaram em virtude das mudanças ocorridas na sociedade capitalista nas últimas décadas. Decorre daí a impossibilidade em se comparar as juventudes entre gerações, fato que ocasiona uma série de preconceitos e estereótipos.

Isto nos leva a considerar, em terceiro lugar, a impossibilidade de retratar a juventude como um conceito unívoco, por razões tanto históricas, quanto sociais e culturais, jogando por terra o mito da juventude homogênea (MARGULIS; UREESTI, 1996) que identifica todos os jovens a partir de um modelo único, como se houvesse na sociedade uma distribuição igual de oportunidades que permitisse a todos os jovens desfrutar da condição juvenil da mesma forma. Contrário a essa concepção, para Bourdieu (1983) existem diferentes atributos sociais que impedem a representação da juventude e dos jovens como uma unidade social. Os diversos e desiguais contextos sociais marcam a forma de "ser jovem", tanto entre sociedades diversas, como no interior de uma mesma sociedade, o que faz com que a condição juvenil seja vivida de forma desigual, sendo, portanto, "um formidável abuso de linguagem que se pode subsumir no mesmo conceito, universos sociais que praticamente não possuem nada em comum" (BOURDIEU, 1983, p.114).

Apesar do reconhecimento da impossibilidade de retratar a juventude como um conceito homogêneo, uma vez que os jovens vivenciam aspectos diferenciados, de acordo com suas condições econômico-sociais, gênero, etnia, sexualidade, local de moradia, entre outras variáveis, este estudo visa a somarse aos demais trabalhos que buscam compreender os diferentes modos de perceber, sentir e estar no mundo dos jovens das camadas populares na 
atualidade; refletindo as mediações e contradições que determinam serem quem são.

Trata-se de reflexões preliminares, tecidas a partir de dados da pesquisa em andamento - realizada com estudantes do Ensino Médio, na modalidade da Educação de Jovens e Adultos (EJA), do turno noturno, de duas escolas pertencentes à rede estadual de educação do Rio de Janeiro, localizadas no entorno de três das maiores favelas da cidade - a Rocinha, situada na Zona Sul da cidade, a do Jacarezinho e Manguinhos, ambas situadas na Zona Norte. A pesquisa é de cunho qualitativo e empírico, e tem o materialismo históricodialético como matriz teórica e metodológica, tendo se utilizado até o momento do seguinte percurso metodológico: entrevistas de roteiros semi-estruturados aplicados a 32 jovens, na faixa etária de 18 a 29 anos de idade, e a realização de dois grupos focais, que contou com a participação de 10 jovens de cada unidade escolar.

As questões dos referidos instrumentos buscaram compreender o perfil dos jovens estudantes-trabalhadores de hoje e os sentidos/percepções que imprimem a participação política e a relação trabalho e educação no atual contexto de desemprego estrutural e de crescimento das relações de trabalho flexiveis e precárias, caracterizadas pela terceirização, trabalho de tempo parcial, autônomo e/ou desregulamentado, fato que tende a se agravar com a reforma trabalhista implementada no governo Temer por meio da Lei n. $13.467 / 2017$.

$\mathrm{O}$ argumento aqui defendido parte do pressuposto dos jovens enquanto produto/produtor histórico-social; sintese das múltiplas relações estabelecidas por meio das transformações objetivas ocorridas no mundo da produção e do trabalho no Brasil, em decorrência da adoção do regime de acumulação flexível do capital e da política neoliberal, após a década de 1990. Intenta demonstrar que as marcas do individualismo, do imediatismo, da incerteza, do consumismo e do ceticismo em relação à política institucionalizada, entre outras subjetividades sinalizadas pelos sujeitos da pesquisa, são uma construção 
histórico-cultural e que têm sido retroalimentados por meio de diversos "aparelhos de hegemonia", no sentido gramsciano.

Para a realização desse objetivo, na primeira parte descrevo um breve histórico das políticas públicas de juventudes no Brasil, no intuito de evidenciar a luta da população juvenil para a afirmação enquanto sujeitos de direitos, merecedores de atenção por parte de políticas específicas. Em seguida, busco analisar o perfil dos jovens pesquisados, especificamente sua identidade cultural e subjetividades, como sintese das mudanças ocorridas nas determinações objetivas de reprodução da vida efetuadas com a adoção do regime de acumulação flexível no Brasil, no contexto da década de 1990. Sendo assim, justifica-se a centralidade conferida à esta década/contexto no decorrer do presente texto.

\section{Breve histórico das politicas de juventude no Brasil}

O governo Lula teve um papel importante na instauração de uma política de juventude no país. Tal reconhecimento, no entanto, chegou com certo atraso se compararmos o Brasil com os demais países latino-americanos, onde as questões da juventude entraram na pauta de políticas públicas ao longo da década de 1990. O estabelecimento do Ano Internacional da Juventude decretado pela ONU, em 1985, e a criação da Organização Ibero-Americana de Juventude (OIJ), em 1992, não foram capazes de estimular à formulação de programas ou organismos específicos de politicas para este grupo populacional, o que fez do Brasil o penúltimo país latino-americano a colocar as demandas da juventude na agenda governamental, ficando a frente somente de Honduras.

O reconhecimento da criança e adolescente como sujeitos de direitos pelo Estatuto da Criança e do Adolescente (ECA), em 1990, foi um marco importante para a questão juvenil, pois fez avançar de modo significativo a discussão sobre as politicas de juventude. No entanto, além de contribuir para que o termo juventude ficasse associado à adolescência, jogou para uma zona nebulosa a 
discussão sobre os direitos dos jovens que atingem a maioridade legal (18 anos), uma vez que os deixou fora do alcance das ações e debates sobre direito e cidadania trazidos pelo ECA.

Programas ou politicas para a juventude foram criados somente a partir de 1997, após a repercussão nacional do assassinato em Brasília do índio pataxó Galdino Jesus dos Santos, incendiado por cinco jovens de classe média enquanto dormia em uma parada de ônibus. Destinados aos jovens na condição de risco social e executados em parceria com organizações não governamentais (ONGs) e fundações empresariais, tais programas foram guiados pela idéia de prevenção de delitos, de controle ou de efeito compensatório de problemas que atingiriam a juventude, contribuindo para reforçar a imagem do jovem como um problema, especialmente em questões relacionadas à violência, ao crime, à exploração sexual, a drogadição, a saúde e ao desemprego (SPOSITO, 2003). Concebendo o ócio como o causador dos "desvios", os programas de natureza esportiva, culturais e de trabalho orientaram-se no controle social do tempo livre dos jovens - daí terem sido executados em regiões marcadas por alto índice de violência e destinados aos jovens em maior estado de vulnerabilidade social, na maioria, pobres e negros. Como assinala Abramo (1997), o foco real da preocupação das referidas políticas era com a coesão moral da sociedade e não por reconhecer o jovem como sujeito de direito.

Ainda hoje são grandes os desafios para o reconhecimento dos jovens como sujeitos de direitos, especialmente em nosso país, cuja história é marcada por mecanismos legais e subjetivos elaborados pela classe dominante-dirigente com vistas à exclusão da participação política e à negação de direitos para grandes setores da população. Ainda que nas últimas décadas a ampliação de direitos tenha ocorrido por meio da legislação nacional, na realidade concreta esta ampliação se faz de forma fraca e restrita, posto que as condições políticas, econômicas, sociais e culturais que historicamente produzem a exclusão não foram superadas. Como defende Gentili (2009, p. 1063), "é apressado 
considerar que um direito está consagrado simplesmente pela superação parcial das condições que o negavam no passado".

\section{Fragmentos da pesquisa: os jovens da EJA e a produção de subjetividades}

Tendo em vista que o critério de seleção dos sujeitos da pesquisa priorizou jovens-estudantes da EJA, cabe desde já informar que, conceitualmente, compreendemos a EJA muito mais do que processos escolares; corresponde a todos os processos formativos em que jovens, adultos e idosos vivenciam ao longo da vida, conforme concepção consolidada na $\mathrm{V}$ Conferência Internacional de Adultos (CONFINTEA), realizada em Hamburgo, em 1997. Por ser o Homem um ser social, produto e produtor das múltiplas relações sociais as quais participa, a escola é apenas um dentre muitos espaços na sociedade onde as pessoas constroem e partilham seus conhecimentos.

Todavia, pensar a EJA escolar na perspectiva da formação humana exige concebê-la para além do viés instrumental, economicista e fetichizado que a tem caracterizado, isto é, enquanto redentora das mazelas enfrentadas pelos indivíduos no mercado de trabalho. Exige analisar não só as condições materiais de existência dos jovens, mas considerar a subjetividade como uma construção histórico-cultural; elemento importante dessa materialidade. Por esta razão, a pesquisa tem se dedicado em compreender as ideias e comportamentos dos jovens no movimento de transformações das determinações objetivas.

Grosso modo, os jovens participantes da pesquisa vivem as mazelas comuns enfrentadas pelos jovens de baixo poder aquisitivo e moradores das áreas de risco. Entre os 32 jovens pesquisados, 11 (34\%) se encontravam em situação de desemprego. Dos estudantes inseridos no mercado de trabalho, 15 encontravam-se no mercado de trabalho formal (47\%), com alguns direitos trabalhistas garantidos, ao passo que $6(19 \%)$ exerciam atividades no mercado 
informal. Quanto à renda familiar, 21 jovens (65\%) informaram ser composta entre 1 e 2 salários mínimos; 2 indicaram que era constituída por menos de um salário, enquanto $6(18 \%)$ indicaram que correspondia entre 2 e 3 salários. Não obstante três estudantes não tenham informados sua renda familiar, os dados demonstram a degradação das condições objetivas de reprodução da existência intensificada nos últimos três anos em decorrência da (suposta) crise vivida no Estado do Rio de Janeiro.

No aspecto social, a maioria convive com a violência no seu cotidiano, entre ela, a própria violação de direitos por parte do Estado. Por sentirem de forma imediata os efeitos do narcotráfico e do crime organizado, quantitativo significativo desses jovens circula pouco pela cidade, devido à espacialidade determinada não só pelo crescimento da violência e do narcotráfico no Rio de Janeiro, mas também por fatores de ordem econômica que ocasionam a desigual apropriação e circulação dos sujeitos das diferentes classes sociais da/na cidade. Para $60 \%$ dos jovens pesquisados, grande parte de seus momentos de lazer e de demais formas de socialização ocorrem no próprio bairro onde residem, com exceção da socialização promovida pela a escola e/ou o trabalho.

Reconhecendo não se tratar de uma questão irrelevante ou menor, a cidade foi considerada elemento importante nas politicas de juventudes durante os governos Lula da Silva e Dilma Roussef, sobretudo, por tais politicas pautarem-se em uma concepção de cidadania participativa e no protagonismo juvenil. Não por acaso, "Juventude e Cidade" foi o principal eixo temático da III Conferencia Nacional de Juventude, realizada em Palmas, em 2010. Isto, porque é na cidade que se materializa a ação política dos seus habitantes; ela é o espelho da forma como a cidadania é vivenciada coletivamente. Por esta razão, a facilidade/dificuldade de acesso que a cidade possibilita aos diferentes equipamentos públicos de cultura, esporte, lazer, saúde, educação, tecnologia, informação, entre outros, é elemento importante na constituição do ser social e não deve ser negligenciada nas análises das questões sociais, como salienta 
Harvey (2004)

Produto do seu tempo, os jovens das escolas pesquisadas expressam em suas narrativas as marcas objetivas e subjetivas das mudanças de corte neoliberal efetuadas no Brasil, a partir da década de 1990, visto que nasceram e se constituíram - individualmente e socialmente - ao longo dessa década. As denominadas políticas de ajustes estruturais implementadas no país, orientadas pelos organismos financeiros multilaterais, principalmente o Fundo Monetário internacional (FMI), a Organização Mundial do Comércio (OMC) e o Banco Mundial, produziram graves consequências sociais. Sob o argumento de reduzir custos e criar melhores condições de competitividade no mercado global uma nova engenharia na produção foi adotada, ocasionando desastrosas mudanças no mundo trabalho, tais como o aumento exponencial do desemprego conjugado com o crescimento do trabalho parcial, temporário e terceirizado, bem como a desregulamentação e o ataque as leis trabalhistas (ANTUNES, 2003; HARVEY, 1994).

Os jovens foram os que mais sofreram com as transformações ocorridas na América Latina ao longo da década de 1990. O estudo "Tendências Mundiais do Emprego Juvenil" da Organização Internacional do Trabalho (apud BRANCO, 2005) mostrou que na última década do século XX, na América Latina e Caribe, a taxa de desemprego entre pessoas com 15 a 24 anos passou de $14,4 \%$ para $16,6 \%$. Segundo o referido estudo, no período entre 1993 e 2003 a oferta de empregos para a faixa de trabalhadores entre 15 e 24 anos expandiu apenas $0,2 \%$, enquanto o crescimento da população mundial das pessoas dessa faixa etária foi de $10,5 \%$, o que levou a taxa de desemprego juvenil ser o dobro da taxa geral.

Em específico ao Brasil, Pochmann (2000) informa que na década de 1990 as ocupações por conta própria foram as opções mais viáveis de inserção dos jovens no mercado de trabalho. Elas tiveram um aumento de $51 \%$, ao passo que o emprego assalariado para os jovens foi reduzido em $22,8 \%$. Ao final daquela década, a média entre dez ocupados com idade entre 15 e 24 anos era 
de quatro autônomos para seis assalariados vivendo toda a precariedade do trabalho autônomo: baixos rendimentos, instabilidade ocupacional, altas jornadas de trabalho, alta rotatividade e ausência de mecanismos de proteção social e trabalhista. Ainda segundo o autor (2007), isto pouco se alterou durante o primeiro mandato do governo Lula da Silva (2003-2006), pois só uma, em cada dez vagas com carteira assinada abertas no Brasil foi ocupada por alguém que procurava se colocar no mercado pela primeira vez.

Com as mudanças operadas no mundo da produção e do trabalho, iniciada nos países de capitalismo central ao final da década de 1970 e efetuadas no Brasil a partir da década de 1990, sob o pretexto de solucionar a crise econômica do capital, a ideia do direito humano e social foi fortemente impactada, ao mesmo tempo em que uma nova cultura foi sendo gestada: a da descartabilidade. Na sociedade da descartabilidade não apenas as mercadorias tornam-se facilmente descartáveis, mas também os próprios trabalhadores. E como assinala Harvey (1994, p.258), "mais do que jogar os bens produzidos, significa também ser capaz de atirar fora valores, estilo de vida, relacionamentos estáveis, apego a coisas, lugares, pessoas, modos adquiridos de agir e ser". Volatilidade e efemeridade constituem, assim, características marcantes dessa nova ordem societária. São produtos da globalização e da necessidade do capitalismo transnacionalizado em acelerar o tempo de giro na produção, na troca e no consumo, o que faz com que as pessoas apresentem maiores dificuldades de realizar planos a longos prazos e manterem qualquer sentido firme de continuidade/permanência (HARVEY, 1994; SENNETT, 2001). Valores tradicionais e históricos são rapidamente cancelados e, por conseguinte, as experiências de lutas organizadas são mais facilmente quebradas, pois a ênfase é dada ao individualismo e a fragmentação em detrimento do coletivo.

Sendo assim, buscamos perceber a compreensão e o interesse dos jovens da EJA em relação à política, tendo em vista, por um lado, o fato de alguns estudos apontarem a baixa participação politica dos jovens nos espaços 
institucionalizados (INSTITUTO CIDADANIA, 2004), e, por outro, os movimentos ocorridos em várias cidades do país protagonizados pelos jovens brasileiros, iniciado em São Paulo com o Movimento do Passe Livre, em junho de 2013, e as ocupações das escolas pelos estudantes secundaristas, no ano de 2016, assim como a ocupação da Assembléia Legislativa de São Paulo, no mesmo ano, por centenas de jovens com o objetivo de pressionar os deputados a investigarem o desvio de dinheiro público na compra de merenda de suas escolas. Conforme os dados da pesquisa até o momento, constata-se que a política não é um assunto muito presente nas rodas de conversas dos estudantes da EJA das escolas investigadas. Apenas 8 jovens, todos acima de 24 anos, demonstraram relativo interesse e certo conhecimento a respeito dos recentes fatos políticos ocorridos no país. A pesquisa realizada pela Secretaria Nacional de Juventude, em 2013, também indica que a política não configura entre os cinco assuntos e temas de preocupação dos jovens.

Barbosa (2013), ao pesquisar sobre a participação política e social dos estudantes do Projovem Urbano das cidades de Palmas (TO), São Vicente (SP) e Guarujá (SP) - programa federal criado no governo Lula com o objetivo de proporcionar aos jovens de 18 a 29 anos de idade, num prazo de 18 meses, a conclusão do ensino fundamental, qualificação profissional inicial e despertar novos comportamentos para ações comunitárias - concluiu que 95\% dos jovens que chegavam ao final do curso não se sentiam mobilizados para ações coletivas, embora houvesse uma disciplina específica no currículo (denominada Participação Cidadã) e um conjunto de atividades voltadas a fomentar essa participação. De acordo com o autor, a principal razão para a baixa mobilização dos jovens do programa reside na realidade por eles vivida, em que dada à precariedade da sua existência e das relações de trabalho na garantia da sobrevivência diária, a participação política e social deixa de ser uma prioridade.

A despeito das mediações objetivas, o enfraquecimento dos movimentos coletivos pode ser explicado também pela perspectiva das subjetividades 
produzidas no novo regime de acumulação flexível. Dejours (1999) nos ajuda a compreender esse movimento ao explicitar o processo que culmina na negação do conflito e na tolerância às injustiças vigentes na sociedade. Evidencia que a generalização do sentimento de indiferença ao outro cresce em proporções e ritmos acelerados em contexto de desemprego estrutural. A vergonha do trabalhador em revelar publicamente o sofrimento que vivencia no trabalho, mediante o sofrimento dos desempregados ou daqueles que correm risco de demissão, faz com que ele assuma uma postura de indiferença ao sofrimento alheio. A indiferença ao seu próprio sofrimento acaba por levá-lo a uma atitude de indiferença ao sofrimento do outro, fazendo com que o silêncio, a cegueira e a surdez tornem-se estratégias defensivas dos efeitos da precarização do trabalho, uma vez que a felicidade do trabalhador só está garantida caso se adapte as mudanças ocorridas no mundo do trabalho.

Fontes (2005) também enfatiza o sentimento de indiferença como conseqüência subjetiva da precarização do mundo do trabalho contemporâneo. Para a autora, essa indiferença generalizada é cruel, pois quanto mais se generaliza o sofrimento, mais se solicita das pessoas a produção de "felicidade e a alegria ali onde todos fomos despossuídos das características que, até então, nos asseguravam nossa própria condição humana" (FONTES, 2005, p. 57).

Como as subjetividades são construídas nas relações concretas de produção da vida em sociedade, como indicam Marx e Engels (2009), o agravamento das questões sociais durante a década de 1990 e início da década seguinte, assim como as políticas compensatórias e focalizadas, de alivio a pobreza, adotadas com o objetivo de aliviar as tensões e garantir a coesão social e a governabilidade, nos ajudam a compreender a anulação da política e o recuo do sentimento de pertencimento a uma coletividade e de identificação com os projetos de transformação social, como sinalizam Mattos (2009), Leher e Frigotto (2005). Não se trata, porém, de um fenômeno restrito a população juvenil, mas vivenciado por grande parte da população brasileira. 
Assim, ainda que consideremos o baixo interesse dos jovens das camadas populares em participar das instituições que caracterizam a vida pública, sendo frequentemente comparados com os jovens das décadas de 1960-1980 e, consequentemente, estereotipados como "desinteressados" e "alienados" politicamente, o conjunto das transformações até aqui elencado nos ajuda a compreender o ceticismo que os jovens pesquisados nutrem à política, geralmente associada aos políticos, à corrupção e à impunidade. O resultado desse processo é a desconfiança e o desinteresse em participar dos espaços institucionalizados tradicionais, como partidos, sindicatos, conselhos, associações de moradores ou mesmo grêmios estudantis. Todavia, cabe destacar que a imagem de apatia política dos jovens de hoje não é consenso. Para Novaes (2007), há uma grande dificuldade das gerações anteriores em reconhecer outras formas de participação política juvenil, como, por exemplo, as manifestações de viés cultural, que promovem aos jovens novas formas de pertencimento social, por lhes permitir expressar seus descontentamentos, fazer denúncias e elaborar novos caminhos de participação. Conforme argumentam Novaes e Vital (2005, p.119), "estão em pauta novas questões e linguagem que renovam a politica e (re)inventam possibilidades de o jovem estar e agir no espaço público".

A valorização do individualismo na sociedade capitalista neoliberal é mediação que deve ser considerada na configuração do refluxo da participação política e social dos estratos empobrecidos da população, ainda que não exclusivo a eles. Em contexto marcado pelos altos índices de desemprego, a ameaça constante da demissão produz o crescimento do individualismo. De acordo com Mancebo (2009, p. 83), este é "um dos efeitos dessa nova configuração insegura, pois a ameaça que se abate sobre o indivíduo faz com que ele se feche sobre si mesmo, numa resposta às pressões sociais, sentidas como impossíveis de serem administradas ou controladas." A reatualização da teoria do capital humano se constitui em outra estratégia de reforço ao individualismo, sendo utilizada pelas classes dominantes e dirigentes 
brasileiras para justificar o alto índice de desemprego, sendo concebido como um problema de ordem individual e não um fenômeno social. Segundo o discurso hegemônico divulgado por meio de diversos aparelhos, cabe aos indivíduos buscarem por sua conta própria os meios de inserção no mercado de trabalho, já que as mesmas condições de competição são dadas para todos. Neste sentido, o sucesso é uma questão de meritocracia, decorrência do empenho, dedicação, esforço e/ou qualificação dos indivíduos.

Com base nas entrevistas realizadas, buscamos identificar a imagem que os jovens possuem em relação aos jovens de hoje. Sem atentarem de que no fundo falavam de si, e embora a inteligência seja um atributo marcante dos jovens contemporâneos na opinião de um terço dos entrevistados, predominaram os sentidos e imagens impregnados no senso comum, a saber: a imagem de que os jovens são "rebeldes", "não sabem o que querem", são "egoístas" e "não pensam no futuro". A visão de imediatismo e de certa irresponsabilidade traduzidas nas respostas de que os jovens "não se preocupam com o futuro" e "não sabem o que querem" pode ser compreendida como produto dos valores difundidos na atual sociedade da descartabilidade e da flexibilização. Como assinala Harvey (1999) e Sennett (2001), o futuro passa a ser descontado do presente pelos jovens, principalmente os das camadas populares, diante da perda de um sentido de futuro ao longo prazo, produzido pelas incertezas e inseguranças vivenciadas, tanto no mundo do trabalho, mediante a ameaça da demissão ou por empregos temporários, quanto em outros campos da vida social, como a morte prematura a que estão mais vulneráveis. Assim, quanto mais jovem e maior o grau de precarização de deterioração das condições reais de existência, maior é o desconto do futuro, o que torna compreensivo o presentismo/imediatismo vivido pelos jovens pesquisados, moradores das favelas da Rocinha, do Jacarezinho e Manguinhos.

Ademais, em contexto de desemprego estrutural, são considerados privilegiados os trabalhadores que se encontram inseridos no mercado de trabalho formal, ainda que sejam, em certos casos, relações de trabalho de 
super exploração. E para manterem-se em condições de empregabilidade, além da aquisição de novas competências e habilidades flexiveis (GENTILI, 1998), é preciso evitar o conflito; apagar o sentimento de pertencimento e de solidariedade de classe, a fim de que não se percebam enquanto trabalhadores e sim "colaboradores" e "parceiros" que se esforçam para que a empresa não quebre. Essas subjetividades demonstram que o capital explora não só a força física dos trabalhadores, mas também seus corações e mentes, revestindo-se em uma exploração psicofísico, como salienta Gramsci (1995).

As transformações operadas pelas Tecnologias da Informática e da Comunicação (TICs) nas relações concretas de produção da vida em sociedade também contribuem para a compreensão da identidade cultural dos jovens pesquisados, especialmente por reconhecer que as TICs têm provocado mudanças no quadro de valores da sociedade que afetam as condições de vida das pessoas, suas rotinas e seu cotidiano (SEVCENKO, 2001). As novas tecnologias, ao provocar a compressão do tempo-espaço de giro da produção, da troca e do consumo alteram as formas das pessoas se relacionarem, sentirem prazer, desejarem, se enxergarem a si e os outros e a viverem.

A globalização e o ímpeto de expansão impelem o capital a eliminar as barreiras espaciais e subjetivas que possam pôr em risco a livre circulação e o consumo em escala planetária das mercadorias. Se a roldana que move o capitalismo é o consumo, mais do que nunca "falsas necessidades" são produzidas e é grande o poder da mídia neste sentido, "na organização do consumo e da produção, bem como na definição de desejos e necessidades integralmente novos" (HARVEY, 2004, p.90). Os jovens pesquisados não estão isentos desse processo. São alvos fáceis da onda imagética e consumista, por sentirem em seu cotidiano a predominância do ter em detrimento do ser, a prevalência de que as pessoas valem pelos bens materiais que possuem (ou que ostentam ter) e não pelos seres humanos que são. Sobretudo, no acelerado ritmo da vida urbana, em que as pessoas estão sempre ocupadas e a forma prática de conhecer e identificar umas as outras é a mais rápida e direta: pela 
maneira como se vestem, pelos objetos simbólicos que exibem, pelo modo e tom com que falam e pelo seu jeito que se comportam. Em outras palavras, como afirma Sevcenko (2001, p. 64), "sua visibilidade social e seu poder de sedução são diretamente proporcionais ao seu poder de compra". Esse apelo ao consumo a determinados símbolos (marcas de roupas, calçados, eletrônicos, ornamentos etc) é algo muito forte entre os jovens pesquisados, pois se constitui em uma estratégia para que se sintam pertencentes, aceitos e incluídos em um mundo de exclusões no qual convivem e sob os olhares de desconfiança de que são alvos. Afinal, como afirma Sevcenko (2001), na atual sociedade as imagens tornam-se mais importante que os conteúdos.

Os jovens da pesquisa são produtos e produtores desse mundo inseguro, incerto, efêmero e de contatos superficiais, em que pessoas, mercadorias e valores tornam-se obsoletos e descartáveis num ritmo alucinado. Em sua maioria, acabam construindo entre suas estratégias de sobrevivência o "pequeno aqui" e o "curto agora". Como indica Hobsbawm (1992, p. 267) "ao subordinar a humanidade à economia, o capitalismo mina e corrói as relações entre seres humanos que formam a sociedade e cria um vácuo moral em que nada conta a não ser o desejo do indivíduo, aqui e agora".

Contudo, mais do que se tecer julgamentos sobre os comportamentos dos jovens com base em imagens estereotipadas, é preciso compreender as mediações que determinam serem quem são. O presente estudo buscou fazer este movimento, tendo priorizado a década de 1990, por compreender que os jovens de hoje nasceram e se constituíram - social e individualmente - no contexto das transformações operadas a partir de então. Eles são síntese dessa processualidade histórica, formados pelas múltiplas relações e determinações objetivas e subjetivas.

Por fim, mas não menos importante, apesar do novo modo cultural de existência aqui descrito, todos nós continuamos a viver sob o domínio do capitalismo, não obstante "homens e mulheres, diante de um momento histórico duro ou fluido, não cessam de engendrar outras formas de existência, 
havendo muitas possibilidades de se responder às demandas que são colocadas por uma dada conjuntura" (MANCEBO, 2009, p. 85). Por ser a subjetividade uma construção, processo histórico-cultural, esta processualidade faz com que as pessoas respondam de muitas maneiras à mesma conjuntura e determinações, sendo portanto, um processo nada linear e tampouco homogêneo, e sim repleto de contradições, assim como é a compreensão da(s) juventude(s).

\section{Considerações Finais}

A partir do pressuposto de que as subjetividades são construídas nas relações concretas de produção da vida em sociedade, buscamos no corpo desse texto identificar os efeitos nos modos de ser, ver, sentir e estar no mundo da população juvenil, de 18 a 29 anos de idade, provocados pelos ajustes estruturais efetuados nas décadas de 1990 no Brasil, em nome da modernização, da resolução da crise econômica e da melhoria das condições de competitividade do país no mercado global. A nova configuração do padrão de acumulação do capital e as mudanças instituídas no mundo da produção e do trabalho produziram não só transformações objetivas na reprodução da existência dos trabalhadores, mas também subjetivas, tais como: a negação do sofrimento, a indiferença, a tolerância as injustiças, o individualismo exacerbado, o imediatismo, a insegurança, a incerteza, o consumismo e o ceticismo a política institucionalizada. Subjetividades essas que estão presentes, de forma direta ou indireta, nas narrativas dos jovens pesquisados e na forma que concebem a relação trabalho e educação.

Todavia, trata-se de uma singularidade no conjunto da totalidade, etapa de um processo amplo, constituído por múltiplas mediações, de natureza objetiva e subjetiva. Assim, mais do que tecer julgamentos sobre o comportamento dos jovens e qualificá-los com base em imagens estereotipadas, é preciso apreender tais mediações. Este foi o sentido que nos orientou, 
embora sem a pretensão de esgotá-la em toda a sua totalidade, diante dos limites circunscritos à escrita do presente texto, bem como do entendimento que toda pesquisa é apenas um recorte aproximativo do real.

\section{Referências}

ABRAMO, H. W. Considerações sobre a tematização social da juventude no Brasil. Revista Brasileira de Educação. São Paulo, n 5-6, p. 25-36, 1997.

ANTUNES, R. Os sentidos do trabalho. São Paulo: Boitempo, 2003.

BARBOSA, C. S. Nova sociabilidade do capital e a natureza das politicas para jovens trabalhadores no governo Lula: uma análise da "participação cidadã" no Projovem Urbano. 2013, 209 p. Tese (Doutorado em Politicas Públicas e Formação Humana). Rio de Janeiro. Universidade do Estado do Rio de Janeiro, 2013.

DEJOURS, C. A banalização da injustiça social. 2 ed.Rio de Janeiro: FGV, 1999.

FONTES, V. Reflexões im-pertinentes: história e capitalismo contemporâneo. Rio de Janeiro: Bom Texto, 2005.

FRIGOTTO, G. Brasil e a política econômico-social: entre o medo e a esperança. Revista Observatório social de América Latina. CLACSO, Buenos Aires, $\mathrm{n}^{\circ} 14$, maio-ago., p. 95-104, 2005.

GENTILI, P. Educar para o desemprego. In: FRIGOTTO, G. (Org.). Educação e crise do trabalho: perspectiva de final de século. Petrópolis, RJ: Vozes, 1998, p. 76-91.

GRAMSCI, A. Os Intelectuais Orgânicos e a Organização da Cultura. 9a ed., Rio de Janeiro: Civilização Brasileira, 1995.

HARVEY, D. Espaços de Esperança. São Paulo: Loyola, 2004.

HARVEY, D. A condição pós-moderna. 4 ed. São Paulo: Edições Loyola, 1994.

INSTITUTO CIDADANIA. Projeto Juventude: documento de conclusão. São Paulo, 2004.

LENOIR, R. Objeto sociológico e problema social. In: PATICK, C. et al., Iniciação à Prática Sociológica, Petrópolis: Vozes, 1996, pp. 59-106 2.

Interfaces da Educ., Paranaíba, v.9, n.27, p. 274-293, 2018 
MANCEBO, D. Contemporaneidade e efeitos de subjetivação. In: BOCK, A. M. M. B. (Org.). Psicologia e o compromisso social. 2 ed. São Paulo: Cortez, 2009, p. 75-92.

MARX, K; ENGELS, F. A ideologia alemã. São Paulo: Expressão Popular, 2009. MARGULIS, M. e URRESTI, M. Juventude es más que uma palavra: ensaios sobre cultura e juventud. Buenos Aires: Biblos, 1996.

MATTOS, M. B. Reorganizando em meio ao refluxo: esforços organizativos e reposicionamentos entre movimentos políticos e sociais dos trabalhadores durante o governo Lula. In: XXVIII INTERNATIONAL CONGRESS OF THE LATIN AMERICAN STUDIES ASSOCIATION (LASA), Anais, Rio de Janeiro, 2009.

NOVAES, R. Nada será como antes: notícias das juventudes sul-americanas. Observatório da Cidadania, 2007. Disponivel em http://www.ibase.br/userimages.br/nada.pdf. Acesso em 25/08/2013.

NOVAES, R.; VITAL, C. A juventude de hoje: (re)invenções da participação social. In: THOMPSON, A. A. (Org.). Associando-se a juventude para construir o futuro. São Paulo: Peirópolis Editora, 2005.

POCHMANN, M. A batalha pelo primeiro emprego: as perspectivas e a situação atual do jovem no mercado de trabalho brasileiro. São Paulo: Publisher Brasil, 2000.

SEnNET, R. A Corrosão do Caráter. São Paulo: Cortez, 2001.

SEVCENKO, N. A corrida para o século XXI: no loop da montanha-russa. São Paulo: Companhia das Letras, 2001.

SPOSITO, M. Trajetórias na constituição de políticas públicas no Brasil. In: FREITAS, M.V.; PAPA, F. de C. (Org.). Políticas públicas: juventude em pauta. São Paulo, Cortez, 2003. 